\title{
Evaluation of The Effect of Macroeconomic Variables, Including Crude Oil Prices, Market Exchange Rate and Inflation Rate on the Stock Price Changes in the Tehran Stock Exchange
}

\author{
'Razieh Shakoory Moghadam
}

${ }^{2}$ Abdelkarim Moghadam

1 MSc, Accounting field , Payam Noor University, Iran, E- mail: Roz.shmoghadam@yahoo.com ${ }^{2}$ Associate Prof, Department of Accounting, Payam Noor University, Iran, Email: a_moghad@pnu.ac.ir

\author{
Doi:10.5901/mjss.2016.v7n4s2p59
}

\section{Abstract}

Due to the impact of macroeconomic variables on different parts of the Iranian capital market, in this article the impact of changes in economic variables, including crude oil prices and average market exchange rate and the inflation rate on the stock price changes for 316 member companies of Tehran Stock Exchange as of and for the period of 5 years from the years 1389 to 1393 is examined. In order to accurately evaluate the effects of declared variables, Augmented Dickey - Fuller test and the VAR model with error correction mechanism is used. According to the results of paper, changes in crude oil prices is a significant positive effect on the stock price changes. And changes in inflation rate and average market exchange rate is a significant negative effect on the stock price changes. based on analysis of variance changes in the average exchange rate was the largest share in the stock price changes and inflation rate is the lowest share in the stock price changes. The findings of this paper provides beneficial implications for investors and policy makers.

Keywords: crude oil prices, exchange rates, inflation rates, stocks.

\section{Introduction}

The first and most important factor influencing the investment in the Stock Exchange is the stock price index. Thus, awareness of factors affecting stock prices is very important for investors. Naturally many factors are effective on the formation of information and the views of market parties and ultimately affect stock price. Some of these factors is domestic and As well as Some of these factors is caused by the macroeconomic variables and the global variables. One of the global variables that can affect on the stock price index is oil prices and macroeconomic variables affecting are the market exchange rate and inflation. World oil prices as a powerful endogenous variables affect a lot of variables including stock prices and that are responsible for international monetary and financial developments.

Changes in exchange rates can have two different effects on stock prices: Increase the exchange rate on the one hand lead to increase in revenues of exporting firms and thus lead to increase price of their shares and on the other hand Increase the exchange rate leads to lower profits and lower stock prices of Importer companies of intermediate goods.

Inflation is also one of economic and social problems of the present century economy. Fluctuations in inflation and instability during the time caused by a bug in economic decisions and predictions and it can also hurt the financial situation of companies. In this regard, several studies in both developed and developing countries around the world has been done and achieved different results.

The results of this research could help to advance scientific level capital markets and raise the awareness of the stakeholders.

\section{Theoretical Foundations}

Securities prices (stock) is a good approximation of their intrinsic value and the prices are good signs for the allocation of resources. If a company does well, of course the stock price goes up and if necessary the company will be able to increase its capital. If the shares to be sold at market value, Shareholders also will not hurt. So Stock prices are good criteria for the allocation of resources. But many factors affect stock prices. The behavior of three of these factors are as follows: 
We have several theories for the link between Stock Price Index and inspired macroeconomic variables. Examples of this theory, the Fisher fundamental theory or the theory of interest rate parity in the money markets (irp) , Sharp theory(1964), Portfolio theory(pt), modern portfolio theory(mpt) and arbitrage pricing theory (apt) is discussed.

The Fisher basic equation, argues that The real interest rate is obtained from subtracting nominal interest rates and inflation rate and Stock price change is equal to the Nominal returns rate. Fisher describes the inflation impact on stock returns.

Fama (1891) argued in the Fisher equation, some Monetary macroeconomic variables such as liquidity and interest rates have been ignored. He was to prove a claim, with regard to the relationship between the money market and stock market, the money market equilibrium is studied.

Based on William Sharp ,the Factors affecting on the stock price is classified as follows:

A)Internal factors (micro factors):those factors affecting the stock price in relation to the company's operations and decisions of the company. Such as earnings per share (EPS), dividend per share (DPS), the price earnings ratio (P / E), and other internal factors.

B) External factors (macro factors): These factors outside the company's management authority and influence of the company.

These factors are divided into two categories:

1) Political factors; factors such as war, peace, cessation of political and economic relations with other countries and so on, that all of these factors on stock prices has important roles.

2) Economic factors, the economic recession and economic prosperity are strongly influenced by the Stock Exchange. General economic factors affecting the stock price is divided into two categories:

Real variables: GDP, savings, tax rates, oil prices, etc.

Monetary variables: liquidity, exchange rates, interest rates, consumer price index and inflation.

Portfolio theory: Because of Investors in its asset portfolio are hoarding various combinations of cash, shares, bank deposits, bonds, gold and currencies and stock, Changes in money supply, exchange rates, interest rates and inflation and so on affect People demand to hold shares, the changes in demand for the stock also affect the stock price. Some financial assets such as bank deposits have fixed returns and without risk, And others such as bonds, currencies, etc has uncertain and risky returns. (Karim Zadeh 2006)

This theory gives investors the opportunity to statistically estimate your risk and return on investment. The Modern portfolio theory (mpt) is a normative theory that is provided by economists. In this theory, according to the market standards for the behavior of investors, to build the portfolio is provided. This theory by measuring investment risk and the relationship between risk and expected return, provides a framework for the creation and portfolio selection based on expected returns and investor willing to risk taking. This theory for asset allocation according to the expected return of each asset class and the willingness of investors to build a portfolio optimized towards risk, assets classification is from top to bottom. According to this theory, the universe risk models for portfolio construction and risk taking control were presented. These models can be divided into three categories: statistical factor models, macroeconomic factor models and agent based models.

Arbitrage pricing theory (apt): This theory was proposed by Stephen ross for assets pricing. This theory is a model of financial instruments and also believes that the behavior of the portfolio on the assumption that yields is described based on a structure or operating model. In other words, the expected return on the assets in the portfolio, subject to a linear combination of factors that affect the return on assets. These factors include: statistical indicators, factors relating to the industry and market and macroeconomic variables such as exchange rates, interest rates, inflation, oil prices, industrial production, etc. (Byabany\& Taqavy 2003)

The theoretical framework, energy (oil) is considered as one of the productive inputs in the economy production function. When the input price increases, The profit-maximizing level of output is reduced. From the viewpoint different economic schools, the most important factors affecting economic growth is capital and labor, both specialist and nonspecialist. In The new growth theory The energy factor is also entered into the model But its importance is not uniform In various models.

Some economists, ecologists believe that The energy is a major factor and that is the only factor affecting of production and Labor and capital are mediating factors and They need energy To apply.

On the other hand, neoclassical economists believe that The energy is not an important factor in economic growth and The energy through its impact on labor and capital, will have an indirect impact on economic growth And it does not have a direct effect on economic growth.

Obviously, if energy is a production input, the input price increase has caused an increase in the cost of production and increase in the price of the product and the decline in employment. 
Impact of exchange rate on stock prices in the commodity market approach are discussed and the stock price on the exchange rate effect in the form of approaches, including portfolio approach is discussed.

In the framework of commodity markets, changes in exchange rates on foreign operations firm, and in total will have an impact on corporate profits and stock price also. (Dronbusch \& Fischer1980, Aggarwal 1981)

In terms of investment, inflation as one of the factors in systemic risk. Inflation is one of the factors in systemic risk. And that is also one of the most important indicators in fundamental analysis. Inflation is important because of its impact on the real rate of return. (Real rate of return is equal to the nominal return rate after subtracting inflation rate). The term inflationary shield is also caused by this same concept And as one of the important questions is raised in the case of investment in the Tehran Stock Exchange. In other words, investors are looking for answers to the question of whether to invest in stocks Tehran Stock Exchange can yield at least equal to the rate of inflation or not?

\section{Literature Review}

Nath Sahu and Bandopadhyay (2014) have reviewed Relationship between oil prices and stock prices in India in the period from January 2001 to March 2013, using the Johansen test, vector error correction model (VECM), Granger causality test, impulse response functions (IRFs) and analysis of variance to provide long-term and short-term relationship. The findings of the Johansen test shows long-term relationship. In addition, the vector error correction model represents the path of the Indian stock market in the long-term price of oil, but not vice versa. The results of Granger causality test confirms that there is no short-run causality between variables. Finally, impulse response functions shows a positive shock in oil prices that has a small but dynamic and positive impact on the Indian stock market in the short term can be expressed.

Chinzara(2011) studied the uncertainty relationship between macroeconomic variables and stock price index by using VAR - GARCH model for South Africa.

Masih et all(2011) study the fluctuations in oil prices and their stock price changes. The main objective of this study was to investigate the effect of fluctuations in the price of crude oil during the financial crisis, South Korea. In this study ,the relationship between the variables of interest rates, economic activity, real stock returns, real oil prices and the volatility of oil prices have been studied by using the VECM. The results of this study show that Fluctuations in oil prices has an impact on real stock And this trend has increased over time. Changes in oil prices has significantly influenced the stock market. The analysis of this study have shown that the main stock index real short-term adjustment path is a longrun equilibrium. Shock and Fluctuations in the oil prices will increase the stock returns and then reduce it. Which leads to achieve a long-term equilibrium after a period of time is almost 9 months. During this period, interest rates and oil prices have expanded their effects on stock returns. This concludes confirms the relationship between real economic shock, monetary policy instruments and stock market index.

Zhao (2010) studied the dynamic relationship between real exchange rate and stock prices in China for the period 1991- 2009. The multivariate model (GARCH) was used in this study. The results show that long-term stable equilibrium relationship between real exchange rate and stock prices there. And past changes in the stock market has greater effect on future fluctuations in the exchange market.

Aloui and Jammazi(2009) used MS-VAR model estimate and version of wavelet filter series, to determine the fluctuations of the stock market. According to their results, oil price shocks, do not affect the stock market downturn phase. In addition, oil price shocks temporarily reduce stock market returns in the stock market boom phase. This negative association appears to be specific to the period from 1999.

Christopher Gan et al(2006) were testing the interactions between New Zealand stock indexes and macroeconomic variables for a series of seven monthly data from January 1990 till January 2003 using the co-integration test. Used Economic variables, was included inflation exchange rates, GDP, money supply, interest rates on long-term, short-term interest rate and the current price of local oil retail. Johansen co-integration test results showed that exists a long-term relationship Between New Zealand stock price index and economic variables tested. Granger causality test results also showed that New Zealand's stock price is not the Granger causality to changes in economic variables. And because it is the small size of the New Zealand stock market in the stock markets of developed countries.

Ezatollah Abbasian(2008), has reviewed the impact of macroeconomic variables on the Tehran Stock Exchange's index. In this study, the effect of macroeconomic variables such as exchange rates, trade balance, inflation and interest rates on the stock market index in the years 1998-2005 with quarterly data is examined. The method is used in this study, the co-integration and error correction models, response functions and variance analysis and Implicit reaction function.

Mohammed Vaez Barezany, et al (2007). has reviewed Effects of changes in the dynamics of the control variables on the Stock Exchange of variables by using optimal control in the period 1994-2005. Considering the nature of optimal 
control model, control variables in the systemic macro model must be considered exogenous variables. Thus, The system has solved the equations by VAR. For this model, variable stock-market value and trading volume as the dependent variable and variable exchange rate and the volume of money and government spending and taxes as control variables are considered. The test results show that The value of stock market have a long-term and positive relationship with trading volume and government spending and taxes. and The value of stock market have a long-term and negative relationship with the money supply and exchange rates.

Sadorsky (2003) In a study entitled macro-economic factors affecting the volatility of stock price index by using monthly and daily data for the period June 1986 to December 2000, studied the impact of macroeconomic factors on stock price index used to assess the technology America. A feature of this study was to investigate the relationship between oil shocks and price shocks and stock price index technology. The results of this study confirms the significant positive relationship between the momentum of the technology stock price index in America and these impulses.

lili and zuliu hu(1998) studied The reaction of the stock market in the United States with respect to macroeconomic variables such as inflation, discount rates, unemployment, and industrial output by using four stock price index including Dow Jones Industrial Index 23, Standard \& Poor's 500, Rsl 100025 and Rsl 200026 in the period 1980-1996. They found an unexpected increase in money supply will lead to an immediate increase in interest rates And thus has an impact on future cash flows and the subsequent decrease in the stock price.

\section{Research Methods}

Existing research is based on objective, practical and based on the nature and methods, descriptive and analytical. Research in the period April 2010 to March 2015 is estimated. The population used in this research is the member companies of Tehran Stock Exchange. In this study ,The systematic deletion is used for sampling. For this purpose, all population companies that the following conditions have been chosen and others have been removed:

In order to homogeneity of information, the nature of their activities are not financial intermediaries.

They stock trading during the study period, has not stopped more than a year in the Tehran Stock Exchange.

Finally The sample society includes 316 firm's stock price.

Data collection through review of records at libraries or other information centers and other types of equipment maintenance is performed, That in order to accommodate economic theory with the realities of society, is evaluated relationships between independent variables with the dependent variable by using figures After matching Theories, by using inferential statistics and econometric methods, acceptable or reject the proposed hypothesis is tested. The data from various sites including the official website of the Central Bank and MetaTrader5 Trading Software and Stock Exchange site is used.

\subsection{Hypotheses}

Changes in the price of crude oil on long-term has a positive and significant impact on the stock prices changes.

Changes in the average market exchange rate on long-term has a positive and significant impact on the stock prices changes.

Changes in the average rate of inflation over long-term has a positive and significant impact on the stock prices changes.

\subsection{Independent and dependent variables}

The variables used in this analysis are four main variables that can be expressed as follows:

Dependent variable: at the head of this variable, the dependent variable is the stock price changes.

independent variable: Other variables include changes in oil prices and the average rate of inflation and average market exchange rate are independent variables, that The influence of each of them on the dependent variable is evaluated.

\subsection{Data analysis method}

This model is estimated by using time series data. This requires doing Acceptable stationary test to prevent false regression. To investigate the stationary of variables, was used augmented Dyky- Fuller test. Then, after estimating the relationship between variables, the VAR model is estimated and error correction mechanism model is used to determine 
the speed of adjustment. Then The impulse response test and analysis of variance was used. The Eviews7 software is used in this study.

\section{Analysis Result}

The model used in this study is defined as follows:

$\Delta P S_{t}=c+\alpha \Delta P O_{t}+\beta M E R_{t}+\delta M P_{t}+\varepsilon_{t}$

Which in this pattern:

$\triangle P S_{t}=$ Stock price changes

$\triangle P O_{t}=$ oil prices Changes

$M E R_{t}=$ Average exchange rate

$M P_{t}=$ The average rate of inflation

$\varepsilon_{i}=$ Error Term

$c=$ Width of the origin model

Normally, in the estimate based on time series data First of all the time series must be stationary. Static means that the mean and variance are constant over time and the covariance between the two time periods, only depend on the distance or interval between the two periods and have nothing to do with real-time calculation of covariance. If not static time series data, variables show a strong tendency to move in the during the time. And therefore can be seen high $R^{2}$ is not due to the true relationship between variables and that is caused by the time variable And this is a problem that will reduce the accuracy of the estimates. Unit root test is used to detect stationary the time series.

By using augmented Dickey-Fuller unit root test (ADF), If the absolute value of the t-statistic computing of the absolute value of critical computing (Dickey-Fuller test) is larger, then the hypothesis is acceptable based on the fixed time series And the time series is static or steady or stationary . Dickey Fuller unit root test (ADF), revealed that all variables are stationary at the level.

The results in Table (5-1) are provided:

Table 5-1. Dickey Fuller (ADF) unit root test results:

\begin{tabular}{|c|c|c|}
\hline Variable & Computational statistics ADF & Result \\
\hline$\Delta P S_{t}$ & -3.5603 & Static \\
\hline \multirow{2}{*}{$\Delta P O_{t}$} & $(0.01)$ & \multirow{2}{*}{ Static } \\
\hline \multirow{2}{*}{$M E R_{t}$} & -4.8619 & Static \\
\hline \multirow{2}{*}{$M P_{t}$} & $-3.01)$ & Static \\
\hline ADF critical value statistics at 5\% & $(0.01)$ & - \\
\hline
\end{tabular}

Reference: Results

As can be seen above condition applies in the (5-1) table. and All variables of the model at the level are static. So Ordinary least squares method can be used. Ordinary least squares estimators, is the best linear unbiased estimator . In other words, when the variables are steady at the level, means that the hypothesis of co integration is excluded and ordinary least squares method is used.

The results OLS study is reported in the following (5-2) equation:

$\Delta P S_{t}=1.434573+0.410263 \Delta P O_{t}-0.181352 M E R_{t}-0.262312 M P_{t}$

$$
t: \quad[6.7480] \quad[5.0018] \quad[-3.3049] \quad[-4.6374]
$$

$\bar{R}^{2}=0.73$

$D W=1.82$

$F=63.70$

Reference: results

According to equation (5-2) can be seen that Changes in oil prices had a significant positive effect on the size of 
$0 / 41$ on the stock price changes. On the other hand, the average exchange rate and the average inflation rate have negative and significant effect on the size $-0 / 18$ and $-0 / 26$ on stock price change.

Fisher statistical significance (63/70) at the $5 \%$ level represents the estimated overall model is significant. The Durbin-Watson statistic (1/82) showed no problem first-order serial autocorrelation in the disturbing elements estimated model, so The results of the estimated model are not false And can be relied upon. Adjusted coefficient of determination shows that independent variables the study explains about 73 percent of the dependent variable.

As can be seen, Oil prices index have been a significant factor that fulfills our expectations of the stock price functions which states that With rising incomes, the price increases by a factor of less than one. As well as positive intercept indicates that when the independent variables is zero, there is a minimal amount of stock prices.

Tests on the residuals: Normality test, correlation LM test and model Specification Error is reported in this segment.

\subsection{Normality test}

Normality test provides histogram residuals and Jarque-Bera statistic for normality, plus a series of simple descriptive statistics residuals. Using the results of this test, such as elongation, skewness, Jarque-Bera, about the normal distribution of residuals can be used to make decisions.

According to the normality test, the values of (Jarque-Bera) is (0/47) and the probability is the (78 percent), That the normal distribution of residuals is not rejected.

Normality test results are shown in Figure 5-3:

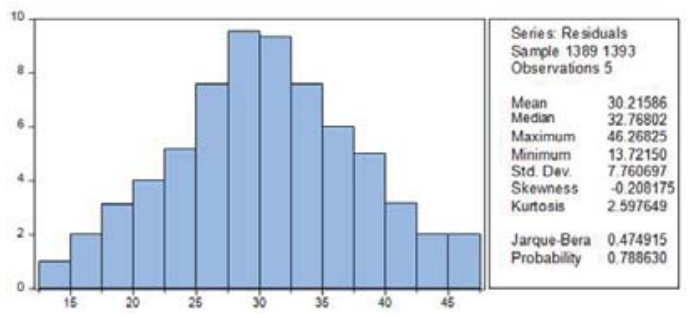

Figure 5-3: Normality Test:

Reference: Research results

\subsection{Autocorrelation test}

Test LM, is the Breusch-Godfrey test, The test is used to detect the presence or absence of Autocorrelation between the residuals And the null hypothesis is the absence of autocorrelation of residuals. The results include $\mathrm{F}$ statistics and $n^{*} R^{2}=$ obs $R$-squared statistics and the corresponding probabilities. If $n^{*} R^{2}=$ obs $R$-squared is smaller than the table $\chi_{a, 2}^{2}$, the null hypothesis is accepted, it means that Does not exist a autocorrelation problem between the model residuals and According to the LM test, the $n R^{2}$ statistic is (5.99) and the probability is(0/04) and the F statistic is (2.99) and the probability is (0/06), and so According to the LM test, can't be rejected the hypothesis of no autocorrelation.

The results of this test are shown in Figure 5-4:

\begin{tabular}{|llll|}
\hline \multicolumn{4}{|l|}{ Breusch-Godfrey Serial Correlation LM Test: } \\
\hline F-statistic & 2.998691 & Prob. F(2,24) & 0.0688 \\
Obs'R-squared & 5.997905 & Prob. Chi-Square(2) & 0.0498 \\
\hline
\end{tabular}

Figure 5-4: Autocorrelation test

Reference: Research Results

\subsection{Model stipulated error test}

Ramsey test, general test is presented to determine the stipulates error, The benefits that can be easily used in its application. If the $F$ computational statistics is greater than the $F$ Table statistics, This means that you can accept the 
Bad stipulates hypothesis of the model, And vice versa if the $F$ computational statistics is smaller than the $F$ Table statistics, the Bad stipulates hypothesis of the model is rejected And thus Has been made a good fitting of the model. Ramsey test, is a general test to determine the stipulates error Which is provided by a scholar named Ramsey. To do this test must add the new explanatory variable to the main regression. the null hypothesis In this test proves The correctness of Designed pattern. This test returns is the F statistic and likelihood ratio log statistic and the possibilities related to it. Ramsey test is applicable only for equations that are satisfied by OLS. Accordingly, the Ramsey RESET test with The $F$ statistic is (0/99) and the probability (61\%) and the log likelihood ratio (0/39) with probability (34\%) shows the correct specification of the model .

The results of this test are shown in Figure 5-5:

\begin{tabular}{|c|c|c|c|}
\hline \multicolumn{4}{|c|}{$\begin{array}{l}\text { Ramsey RESET Test } \\
\text { Equation: UNTITLED } \\
\text { Specification: PS C PO MER MP } \\
\text { Omitted Variables: Squares of fitted values }\end{array}$} \\
\hline $\begin{array}{l}\text { t-statistic } \\
\text { F-statistic } \\
\text { Likelihood ratio }\end{array}$ & $\begin{array}{l}\text { Value } \\
2.644410 \\
0.992902 \\
0.399147\end{array}$ & $\begin{array}{l}\text { df } \\
25 \\
(1,25) \\
1\end{array}$ & $\begin{array}{l}\text { Probability } \\
0.0139 \\
0.6123 \\
0.3427\end{array}$ \\
\hline
\end{tabular}

Figure 5-5: Stipulated Error Test

Reference: Research Results

The results of vector error correction model is given in the Appendix And error correction coefficient is significant and negative. The value of this coefficient is equivalent to $-0 / 85$, meaning that if a shock is to model each year, 85 percent of these imbalances would be adjusted. This means that if a shock is entered to the model each year, 85 percent of these imbalances would be adjusted.

\subsection{Impulse response functions (IRFs)}

Impulse response functions such as analysis of prediction error, is a displayed of moving average of the pattern VAR or VECM. IRFs, show the dynamic behavior of the model's variables to when single tap on any of the variables over time . These impulses are elected usually the size of a standard deviation. Therefore, they say momentum or impulse unit. Origin or starting point responder variable, is the values of the steady-state device (without shocks). In this study, using impulse response function, dynamics instrument unit impulses imposed by any of the variables device is specified.

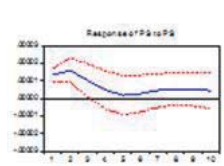

sasencomonats

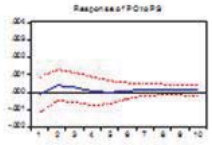

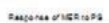

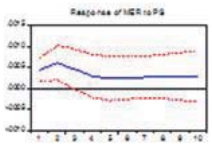

sacenumenses

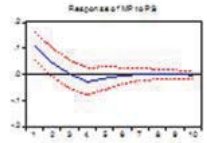

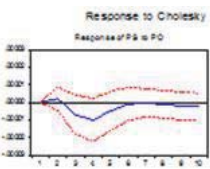

anencoursos:00

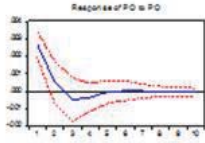

secencunstoso

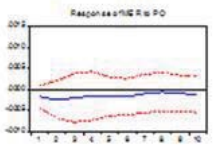

satencurse so

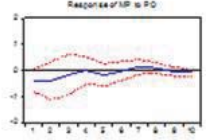

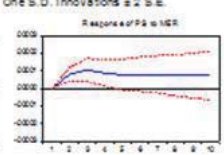

amsencosos sas

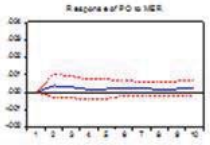

smencurses o is:

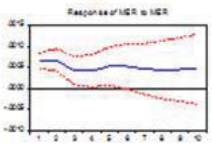

sacentures a 15:

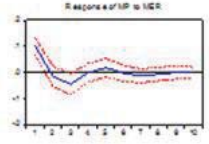

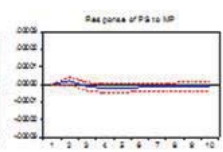

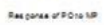
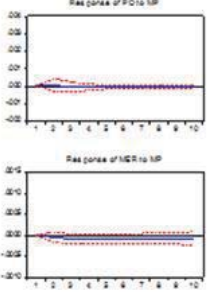

sanemerome

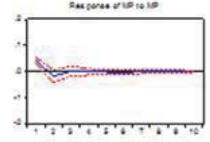

Figure 5-6: Impulse Response

Reference: Research Results 
Chart (5-6) represents answered all model variables to other variables shocks in the research model .As it became clear all variables are sensitive to shocks to the model And have shown reactions in the short-term. But in the long run over time shock effect in the fixed form is affected on the variable And that on the horizon is stable.

\subsection{Analysis of variance}

Analysis of variance offers a method for the analysis of dynamic interactions of shock created in the device. Analysis of variance, measures the proportion or percentage of participation of momentum created in each variable in the variance of Other variables model. Charts(5-7), has shown Results of analysis variance of the stock price.
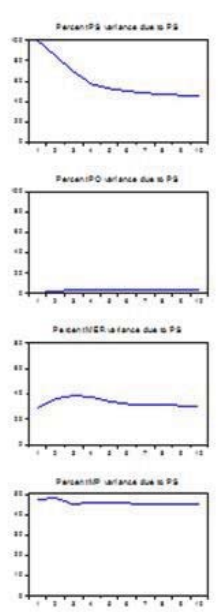

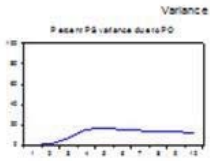

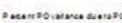

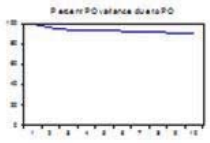

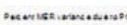

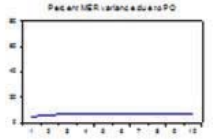

mans wentanos

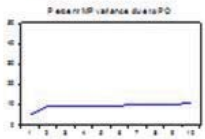

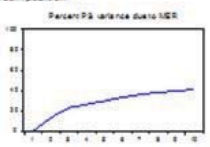

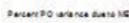
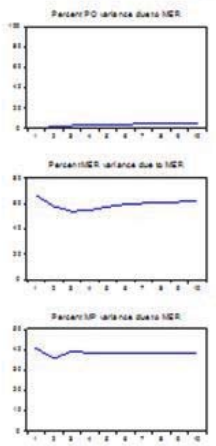

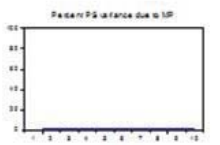

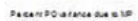
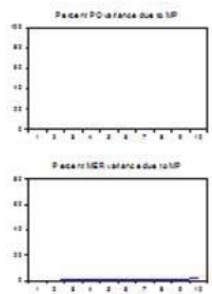

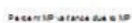

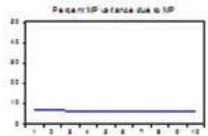

Charts 5-7: Analysis of Variance

Reference: Research Results

As is clear from the results of analysis of variance for variable stock price changes for the 10 period, The highest share in had the changes in exchange rates. Changes in exchange rates had the largest share of the stock price changes. On the other hand changes in the inflation rate had the lowest share of the stock price changes.

\section{Conclusion}

Modern econometric methods for data analysis and hypothesis testing were used In this study And hypotheses have been interpreted. Based on the theoretical framework of research and tests carried out, including Dickey-Fuller unit root test, the model is estimated by using ordinary least squares method and Finally, the hypotheses were tested. According to the estimation results of the model, decisions about hypotheses were as follows:

The first hypothesis:

The first hypothesis was then established that changes in oil prices has a significant and positive effect on the stock price changes. The results showed that the coefficient of variation of oil prices (0/41) with t-student statistic significant, has a positive and significant effect on the stock price changes on the size of $0 / 41$. This means that with a single change in the oil prices Changes, the expectation is that changes in stock prices change as much as 0/41 unit.

Thus the first hypothesis is accepted, it can be said that changes in oil prices has a significant and positive effect on the stock price changes of companies listed on Tehran Stock Exchange during the period April 2010 to March 2015.

The second hypothesis:

The second hypothesis states that the average exchange rate has a significant and positive effect on the stock price changes. Average exchange rate index based on research results is -0/18. According to t-student statistic or the probability ,this result is achievable that with an average exchange rate had significant and negative effect on variable stock price changes on the size of $-0 / 18$. This means that with a single change in the average exchange rate, the 
expectation is that changes in stock prices change as much as -0/18 unit in the opposite direction.

So we can say that the results of this study are consistent with the theoretical foundations. And it can be said that the second hypothesis is that a significant and positive effect of exchange rate changes on the stock prices changes of companies listed on Tehran Stock Exchange during the period April 2010 to March 2015 is not accepted.

The third hypothesis:

The third hypothesis of this study was formulated as follows: The average rate of inflation has a significant positive effect on the stock price changes. The results showed that the inflation rate average is $-0 / 26$. According to the statistic $t$ and the corresponding probability, the average inflation rate had significant and negative effect as much as -0/26 on the stock price changes variable. This means that with a unit change in the average inflation rate expected stock price changes will be changed as much as $-0 / 26$ unit.

Thus it can be stated that the third hypothesis regarding the positive effect of inflation on the average stock price changes has not been confirmed. The third hypothesis of this study was formulated in this way, the average inflation rate and a significant positive effect on the stock price changes.

Summary test of hypotheses is shown in Table 1-5:

Table 5-1. The results of tests Research

\begin{tabular}{|c|l|c|c|}
\hline Number & Hypothesis & Type of test & Test result \\
\hline 1 & Changes in oil prices has a significant positive effect on the stock price changes. & OLS & accepted \\
\hline 2 & Average exchange rate has a significant positive effect on the stock price changes. & OLS & failed \\
\hline 3 & The average rate of inflation has a significant positive effect on the stock price changes. & OLS & failed \\
\hline
\end{tabular}

Reference: Research Results

\section{Limitation of the Study}

Researchers are restricted in their research that part of their manifest themselves at the beginning of work. The main pillars of research, access to data and information. In this regard, access to books, magazines, statistics, databases, etc., in our country is not easy. The lack of any service research on the one hand and having a false culture on the other hand, causes the individuals and institutions to refrain from easy access to the findings and information. It should be noted, unwanted variables that may have resulted from specific designs and methods, and they will be used in the research. These variables Often in different ways, endanger the research internal and external validation. Should be aware that in the Behavioral Sciences Research, control or completely eliminate these factors is impossible. However, Researchers try to predict and identify these factors as much as possible. And apply all necessary precautions to reduce them.

1. The lack of available resources.

2. Lack of access to data and real data of all member companies of the stock.

3. limited number of companies that research has been done about them.

4. inflation is one of the factors that away research's of the actual process.

5. Changing the end date of the financial year some companies will be less than the number of sample members.

6. The lack of similar activities in this field.

7. In each study into various stages, Financial expenditure is essential and certainly Student Research Because of the special investigator of this issue is no exception.

\section{Suggestions}

According to the hypothesis presented suggestions as follows:

1- Increasing oil price changes due to the positive effect on stock price changes indicate improvement of domestic companies in conditions that price changes increases in a positive direction. One side of the coin in this situation, increase the stock price upward change is in favor of shareholders and the other side in this situation says that Fluctuations in the price of oil can cause instability for production companies and indicators Stock Exchange. Therefore offers managers and policy makers must be very clever enough attention to changes in oil prices.

2- Based on the results, Increase in the average exchange rate has a negative effect on the stock price changes. Policy, while the exchange rate is on the rise can be associated with high risk for managers. In this regard, it is 
suggested that in these circumstances managers have adequate preparation for risk management and crisis management.

3- Inflationary conditions always has negative effects on price index in the stock market. Because in the inflationary conditions, companies are having difficulty in determining the actual price And the uncontrolled increase in prices would be wrong to order stock market and stock exchanges. It is necessary that the government should prioritize measures Such as contractionary policies to curb inflation And support package for manufacturing and service companies to be considered.

4- With regard to the practical aspects of the company's stock valuation and stock price prediction great importance, it is suggested that future researchers that in order to judge the relative information content and their growing studied the effect of the earnings components and cash flow on stock prices.

\subsection{Suggestions for future research}

According to the results of research and its limitations for next studies will be offered the following suggestions:

1. Checking The relationship between changes predicted earnings per share of operating earnings (continuous activity) and changes in stock prices.

2. Checking The effect of macroeconomic variables on the capital market variables such as volume and earnings per share and cash returns and so on.

\section{References}

AbbasiAN, E., \& Moradpour Olady, M., \& Abasyvn, V. (2008). The effect of macroeconomic variables on the Tehran Stock Exchange index. Journal of Iranian Economic Research. 12 (36): 135-152. (in persian)

Aggarwal, R. (1981). Exchange Rates and Stock Prices; A Study of the US Capital Markets under Floating Exchange Rate. Akron Business and Economic Review. 12(2): 7-12.

Aloui, C., \& Jammazi, R. (2009). The Effects of Crude Oil Shocks on Stock Market Shifts Behavior: A Regimes Witching Approach. Energy Economics. 31(5): 788-799.

Barzany, S.M., \& Dalaly Esfahani, R., \& Samadi, S., \& Faljv, H.R. (2007). Evaluate the regulatory role of the government in Tehran Stock Exchange Iran within the framework of an optimal control model. Quarterly Economic Bulletin. 10(1): 285-307. (in persian)

Branson, W.H. (1381). Macro economic theory and policy. Translation Abbas shaker. Tehran: Nshrny publications.

Byabany, Sh., \& Taqavy, M. (2003). The effects of changes in market exchange rates and future cash flows on shares of public companies listed on the stock exchange. Quarterly Economic Bulletin. 3(10 and 11):13-38. (in persian).

Chinzara, Z. (2011). macroeconomic uncertainty and conditional stock market volatility in south Africa. south African journal of economics. 79(1): 27-49.

Dronbusch, R., \& Fischer, S. (1980). Exchange Rates and Current Account. American Economic Review. 70(5): 960-971.

Karim Zadeh, M. (2006). Evaluation of long-term relationship between stock price index and monetary macroeconomic variables, using co-integration of the Iranian economy. Journal of Iranian Economic Research. 8( 26: 41-42. (in persian).

Masih, R., \& Peters, S., \& De Mello, L. (2011). Oil price volatility and stock price fluctuations in an emerging market: Evidence from South Korea. Journal of Energy Economics. 33(5): 975-986.

Morley, B., \& Pentecost, E. J. (2000). Common Trends and Cycles in G7 Countries Exchange Rates and Stock Prices. Applied Economic Letters. 7(1):7-10.

Nath Sahu, T ,. \& Bandopadhyay, K. (2014). An empirical study on the dynamic relationship between oil prices and Indian stock market". Journal of Managerial Finance. 40(2): 200 - 215.

Sadorsky, P.(2003). The Macroeconomic Determinants of Technology Stock Price Volatility;Review of Financial Economics. 12(2): 191205.

Zhao, H. (2010). Dynamic relationship between exchange rate and stock price:Evidence from China. Research in International Business and Finance. 24(2): 103-112. 